\title{
OPERATION AND PERFORMANCE OF A SWITCHED RELUCTANCE GENERATOR
}

\author{
M. M. Khater and S. M. R. Tahoun \\ Department of Electrical Engineering, Faculty of Engineering, \\ Menoufiya University, Shebin El-Kom,
}

\begin{abstract}
Former studies have been focused on switched reluctance machine as a motor. This paper introduces an analytical and experimental study on a switched reluctance generator. Two basic operating conditions namely, constant voltage $d c$ source and separately-excited generator with direct load have been proposed and analytically investigated. An experimental study has been carried out on the separately-excited condition and good matching has been obtained between measured and corresponding analytical results. Specific characteristics and suitable applications of this generating system have been discussed.
\end{abstract}

Keywords: Switched reluctance generators.

\section{1- Introduction}

Switched reluctance (SR) machines have been developed over the last two decades. Most studies over this period have been directed to their motoring operation which is now well established. SR machine in its basic form consists of a doubly-salient singly-excited structure[1]. Windings are usually located on

Maunseript Received From Dr. M.M. Khater and Dr. S.M. R. Tahoun, on: 14/10/1998. Accepted on : 26/11/1998.

Engineering Researcth Bulletin, Vol. 22, No. 1, 1999.

Minufiya University, Faculty of Engineering, Shebin El-Kom, EGYPT, iss 1110-1180 
the stator, while the rotor has no windings or magnets. This construction gives many advantages to this type of machine. Among these advantages is the rigged construction which allows very high speed operation. The torque-speed characteristics of such type of motors are quite similar to those of the dc-series motors. These characteristics find various applications in household, general industrial and traction systems[2].

Large number of research work has been documented about this machine as a motor, but a little could be found about SR generators. Being like a dc machine, SR generator has some advantages over the conventional dc ones. One of its major advantages is that there is no limitation on its operating speed since there is no mechanical commutator or brush contacts.

A study considering a load voltage controller for a SR generator connected to a dc electric power system has been reported [3]. That study was mainly restricted to the controller design. Also, the axial field type of SR machine has been proposed as a generator for wind-turbine applications[4]. In that reference, photovoltaic system was used with the generator to provide the essential excitation.

An experimental study considering separately excited SR generator with a direct load has been recently reported[5]. Some experimental results were recorded, however, the external load characteristics have not been investigated. Nevertheless most of the available literature is concerned mainly with theoretical studies rather than experimental investigations.

In this paper analytical and experimental studies for the SR generator are reported. Two different operating conditions are considered. The first condition is the operation with constant voltage dc source. Generator performance has been investigated analytically and simulation results are presented. The second operating condition is concemed with the separately-excited stand alone $S R$ generator with a direct load. Performance characteristics have been investigated analytically and experimentally. A laboratory prototype has been built for this purpose. The analytical and test results are shown to be in good agreement

\section{2- System Description and Principle of Operation}

Considering the output terminals, the switched reluctance generator can be visualized as a brushless dc machine. However, it is different in operation and construction. In dc machines there are two different types of windings for excitation and armature located on different members (stator and rotor). The generated power is collected with brushes using a mechanical commutator. In switched reluctance machines there is only one type of windings located on the stationary member. The second member acts to complete the magnetic circuit 
and to give the suitable reluctance variation according to the relative position with respect to the other member. The machine windings do both the excitation and armature functions alternately. An electronic converter controlled by a shaft position sensor is used to switch the machine windings alternately between the excitation source and the power sink.

Being doubly salient the phase inductance of SR machine alters between maximum and minimum values with the rotor position. The sign of inductance rate of change $(\mathbf{d L} / \mathbf{d} \theta)$ also varies between positive and negative according to whether the inductance is going to the maximum or the minimum. The machine torque can be expressed as:

$$
\mathrm{T}(\theta, \mathrm{i})=\frac{\mathrm{i}^{2}}{2} \frac{\mathrm{d} \mathrm{L}}{\mathrm{d} \theta}
$$

Thus, according to the sign of $(\mathrm{dL} / \mathrm{d} \theta)$ the machine torque will be positive or negative. By adjusting phase excitation pulses to be aligned with the negative sloped $(\mathbf{d L} / \mathbf{d} \theta)$ as shown in Fig(1), the machine will operate in the generating mode. In which case the applied mechanical power is converted to electrical power.

According to the operating conditions, the generated power can be fed to a direct load or injected into a constant voltage source. It should be noted that an excitation source is essential for the machine operation as a generator. Basically, there are two successive operating modes for each phase winding namely; excitation and generation. The power converter changes the function of each phase winding successively. The power switches are switched-on when both stator and rotor poles are aligned (the winding inductance is maximum) to start the excitation mode. In this mode, power is transferred from the excitation source to the machine to increase the fluxlinkage. At the end of the excitation mode, the power switches are turned-off to start the second mode, during which power is directed from the phase windings through the diodes to the load.

Excitation period will be referred-to as a ratio of the negative-sloped inductance period. This is called the commutation ratio. If the negative-sloped period of the inductance waveform is assumed to be equal to the rotor pole $\operatorname{arc} \beta_{\mathrm{r}}$ Then;

Commutation ratio $=\frac{\theta_{\text {off }}-\theta_{\text {on }}}{\beta_{\mathrm{r}}}$

According to the operating conditions, either the machine is excited from the same source into which the generated power is pumped, or a separate source is 
used for excitation and the generated power is directed to a separate load. A constant voltage source is used for the first condition. However in the second condition, a suitable excitation source is essential.

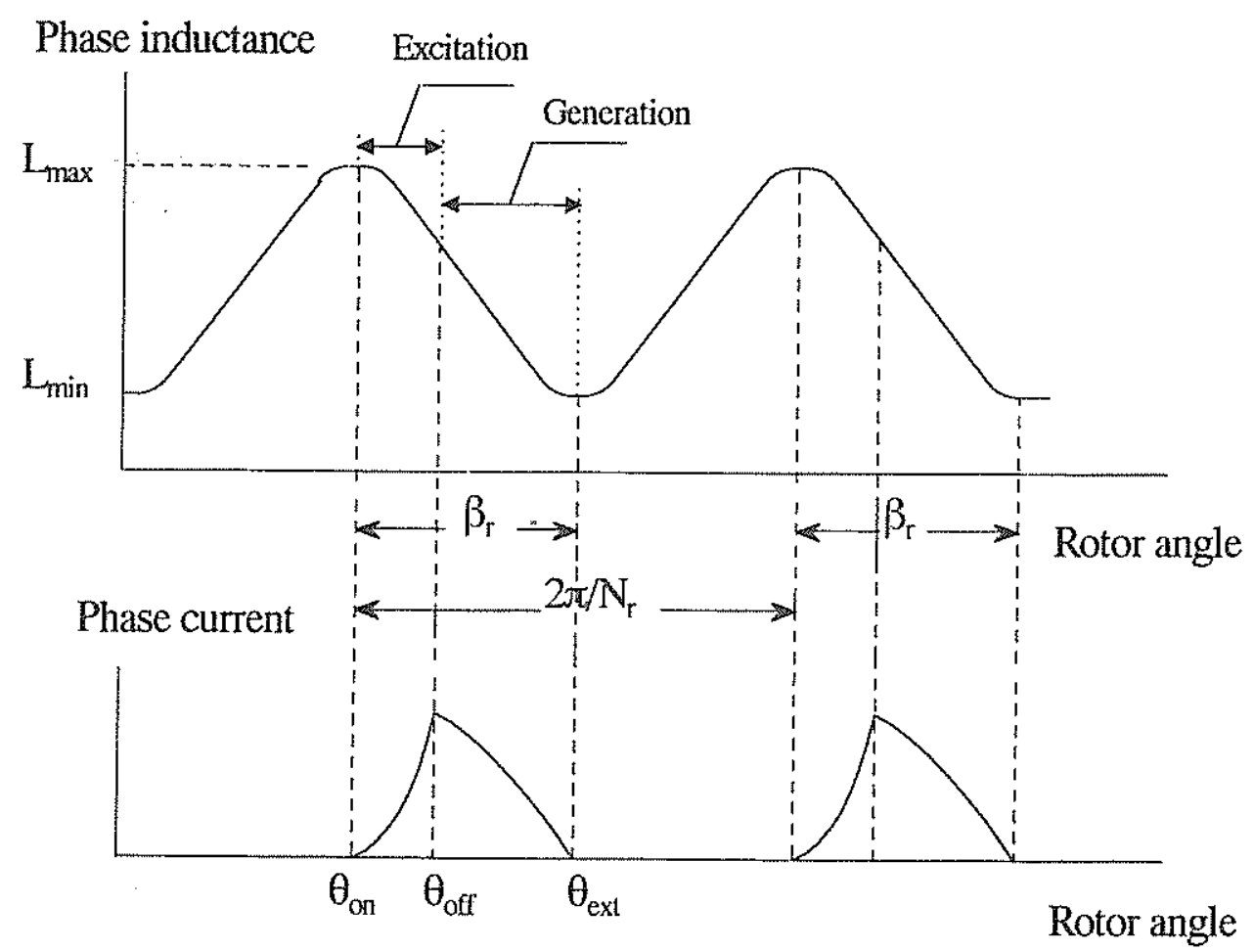

Fig(1) A schematic diagram for phase inductance waveform and phase current pulses for SR machine as a generator

\section{3- Analysis Of The Two Operating Conditions:}

\section{3-1- First operating condition: SR generator connected to a constant voltage dc source:}

In this condition the machine is connected to a two-quadrant dc source. The connection diagram is shown in Fig(2), which is the same for motor operation, but the turn-on angle is delayed to the aligned rotor position.

The voltage equations of phase windings can be written as,

$v_{3}(\theta)=R_{J} \cdot i_{3}+\frac{d \psi_{J}(\theta, i)}{d t}$
$J=1,2, \ldots, n$ 


$$
\begin{array}{rlrlrl}
\mathrm{v}_{\mathrm{J}}(\theta) & =+\mathrm{V} & \text { for } & \theta_{\text {on }} \leq \theta<\theta_{\text {off }} \\
& =-\mathrm{V} & & \text { for } & \theta_{\text {off }} \leq \theta<\theta_{\text {ext }} \\
& =0 & \text { for } & \theta_{\text {ext }} \leq \theta<\frac{2 \pi}{\mathrm{N}_{\mathrm{r}}}
\end{array}
$$

$\mathrm{N}_{\mathrm{r}}$ is the number of rotor poles

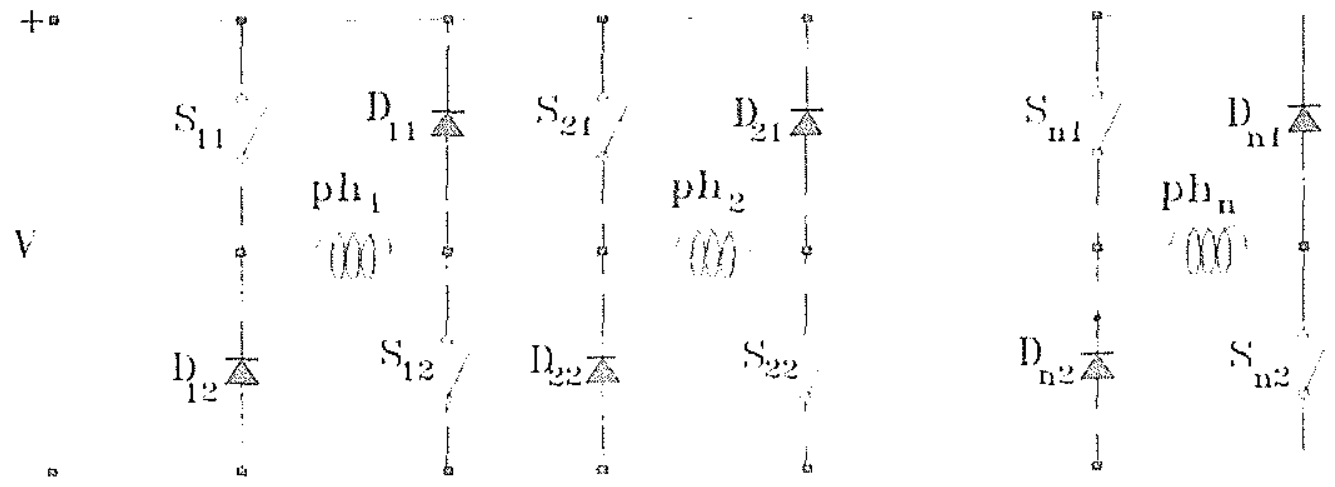

Fig(2) Connection diagram of SR generator with constant voltage dc source.

To obtain the performance of SR generator under this operating condition, two sets of tabulated data are necessary. These sets are the current-fluxlinkage characteristics $\mathbf{i}(\Psi, \theta)$ and the co-energy characteristics $\mathbf{W}(\theta, \mathrm{i})$. These sets of data have been obtained according to the procedure reported in Ref[6].

The fluxlinkage-current curves at both aligned $\psi_{\mathrm{a}}(\mathrm{i})$ and unaligned $\psi_{u}(\mathrm{i})$ rotor positions were obtained experimentally. Another set of fluxlinkage-current curves were predicted for certain intermediate rotor positions by the method described in ref[7]. The whole sets of characteristics were combined together to form a table of $\psi(\theta, \mathbf{i})$. This table has been inverted to the form of $\mathbf{i}(\psi, \theta)$ to be suitable for the analysis. The phase co-energy table $W(\theta, i)$ was obtained by numerical integration of the following equation

$$
W(\theta, i)=\int_{0}^{i} \psi(\theta, i) d i
$$

Numerical integration has been applied to $\operatorname{Eqn}(3)$, to obtain the fluxlinkage waveform. At each integration step the current is updated using the precalculated $\mathrm{i}(\psi, \theta)$ data. The co-energy was predicted at each step using the coenergy table $W(\theta, i)$. Cubic spline interpolation has been used to obtain intermediate values of both data tables. Once the fluxlinkage and phase coenergy have been calculated, each phase current and the total developed power could be obtained. These analyses have been carried-out over a wide range of speeds and the results are given in Figs $(5,6)$. 


\section{3-2- Second operating condition: SR generator with direct load}

The circuit diagram for this condition is shown in Fig(3). Each phase winding is switched-on to the dc source at its aligned position to start the excitation mode. At the end of that mode the power electronic switch is turned-off to start the generating mode. During this mode the generated power is transferred to the load resistance.

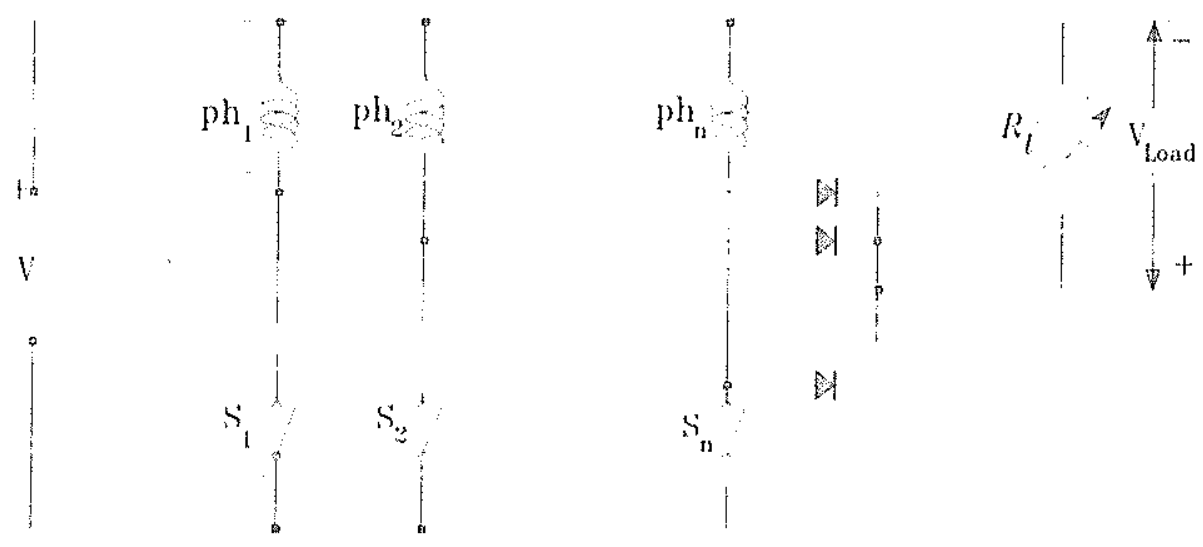

\section{Fig(3) Connection diagram of SR generator with a direct load.}

During the excitation mode the voltage equation for each phase winding can be written as follows:

$$
+V=R_{J} \cdot i_{J}+\frac{d \psi_{J}(\theta, i)}{d t}
$$

$\mathrm{J}=1,2, \ldots, \mathrm{n}$

During generation mode there is no applied voltage and the circuit resistance becomes the sum of phase winding and load resistances. The voltage equation can be written as;

$$
\begin{aligned}
& 0=\left(R_{J}+R_{L}\right) \cdot i_{J}+\frac{d \psi_{J}(\theta, i)}{d t} \\
& J=1,2, \ldots ., n
\end{aligned}
$$

The analysis of this operating condition has been carried-out using the same procedure given for the first operating condition, except that, each phase is represented by the two differential equations $(6,7)$ which are integrated successively. Since the excitation source and load circuit are separate, excitation power, load power and net power were obtained using the terminal variables. The results of these analyses are given in Figs(7-10) along with the corresponding experimental results. 


\section{4- Experimental Study}

An experimental study has been carried-out for SR generator with a direct load. A schematic diagram for the experimental system is shown in Fig(4). This system consists of a 5-phase SR machine[7] mechanically coupled with a DC motor as a prime mover. The shaft position sensor which is mounted on the machine shaft drives a 5-phase MOSFET power converter as shown in Fig(3). The turn-on position and excitation pulse width are controlled digitally using digital control circuits especially designed for this system.

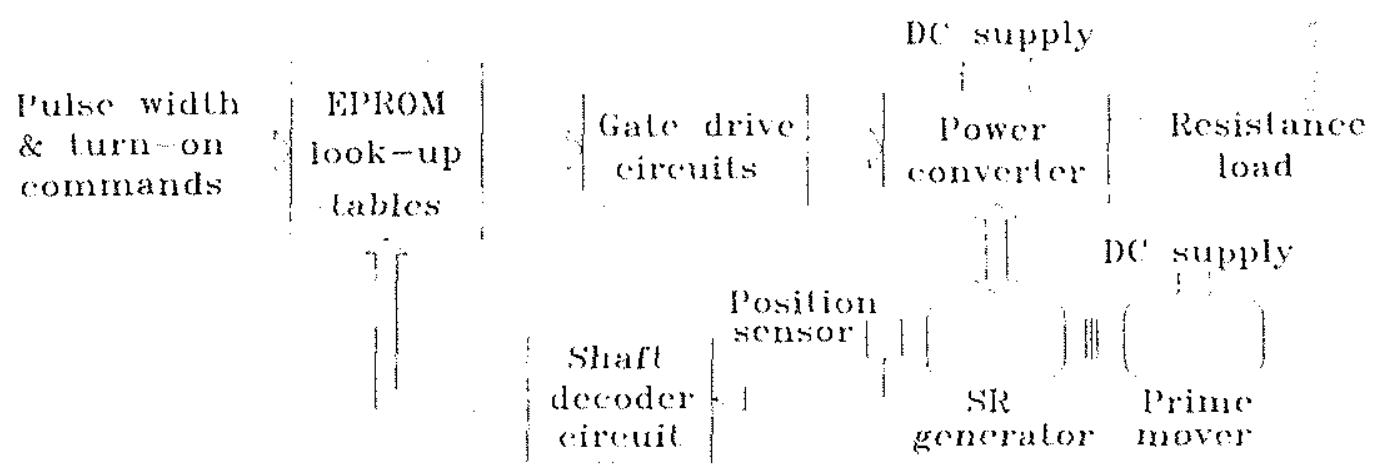

Fig(4) A schematic diagram for the experimental system.

\section{5- Results and Discussion}

For the first operating condition, the system has been analyzed as introduced in section(3). The relation between the generated power and speed, for different commutation ratios, is shown in Fig(5). It can be observed that the power increases with the speed until it reaches a maximum value after which it begins to decrease. At low speeds, chopping is applied to limit phase current to its rated value which permits the generated power to increase with the speed. At maximum power the generated back emf becomes high enough to limit the current level without chopping. At any speed higher than that value, current pulses become triangular and contributes lower power. It is also clear that, the power increases with the increase of the commutation ratio. However, the power decreases for any ratio more than 0.8 . This is due to the prolonged current pulses which extend to the positive sloped inductance periods of the motor operation mode.

The relation between phase current and speed, for different commutation ratios, is shown in Fig(6). The current decreases with the speed increase due to the increase of winding emf.

This operating condition is suitable for wind turbine applications. In such case, the excitation current is obtained from the same voltage source to which the machine is connected. 


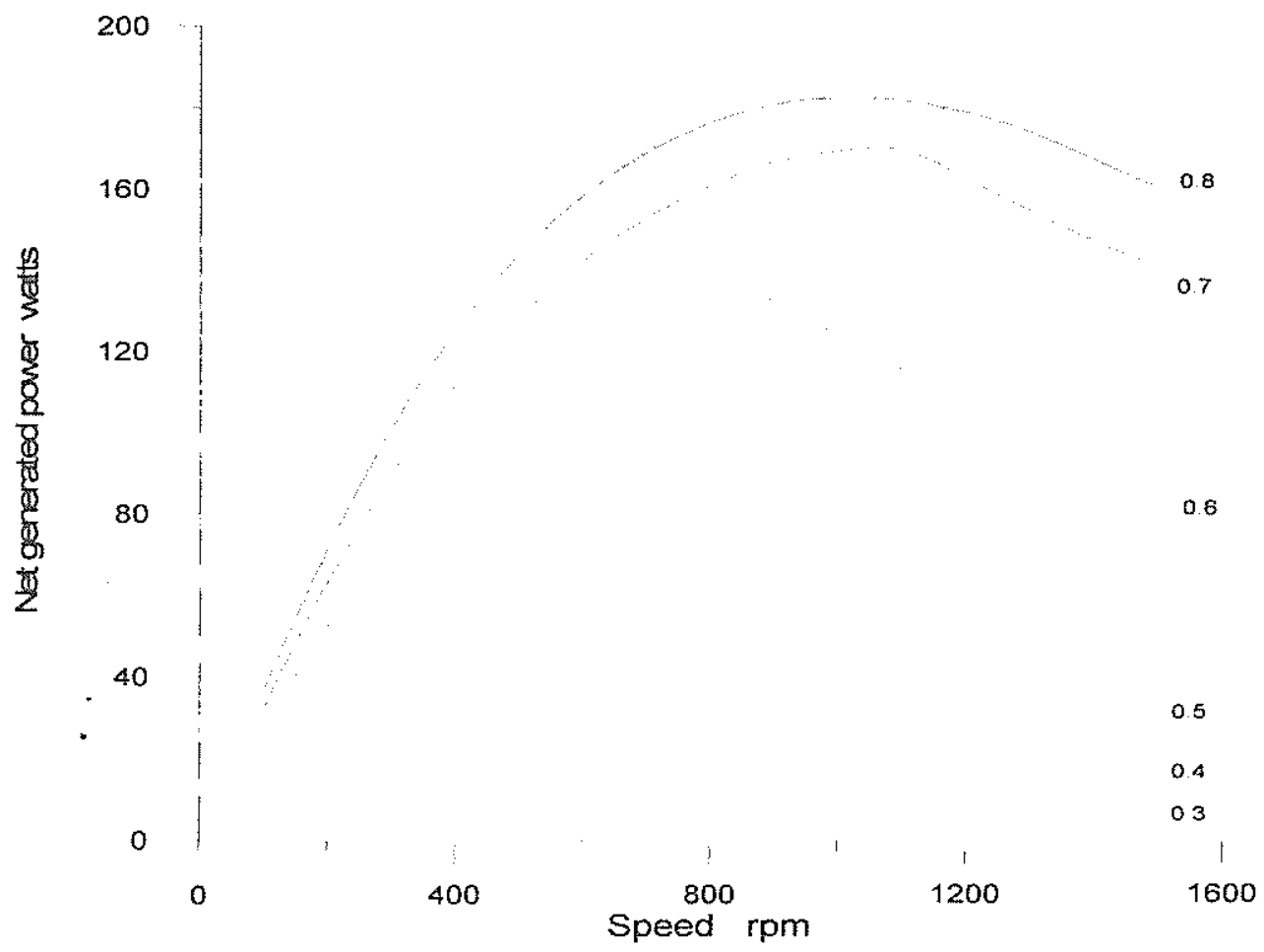

Fig(5) Net generated power as a function of speed for different commutation ratios (For the first operating condition)

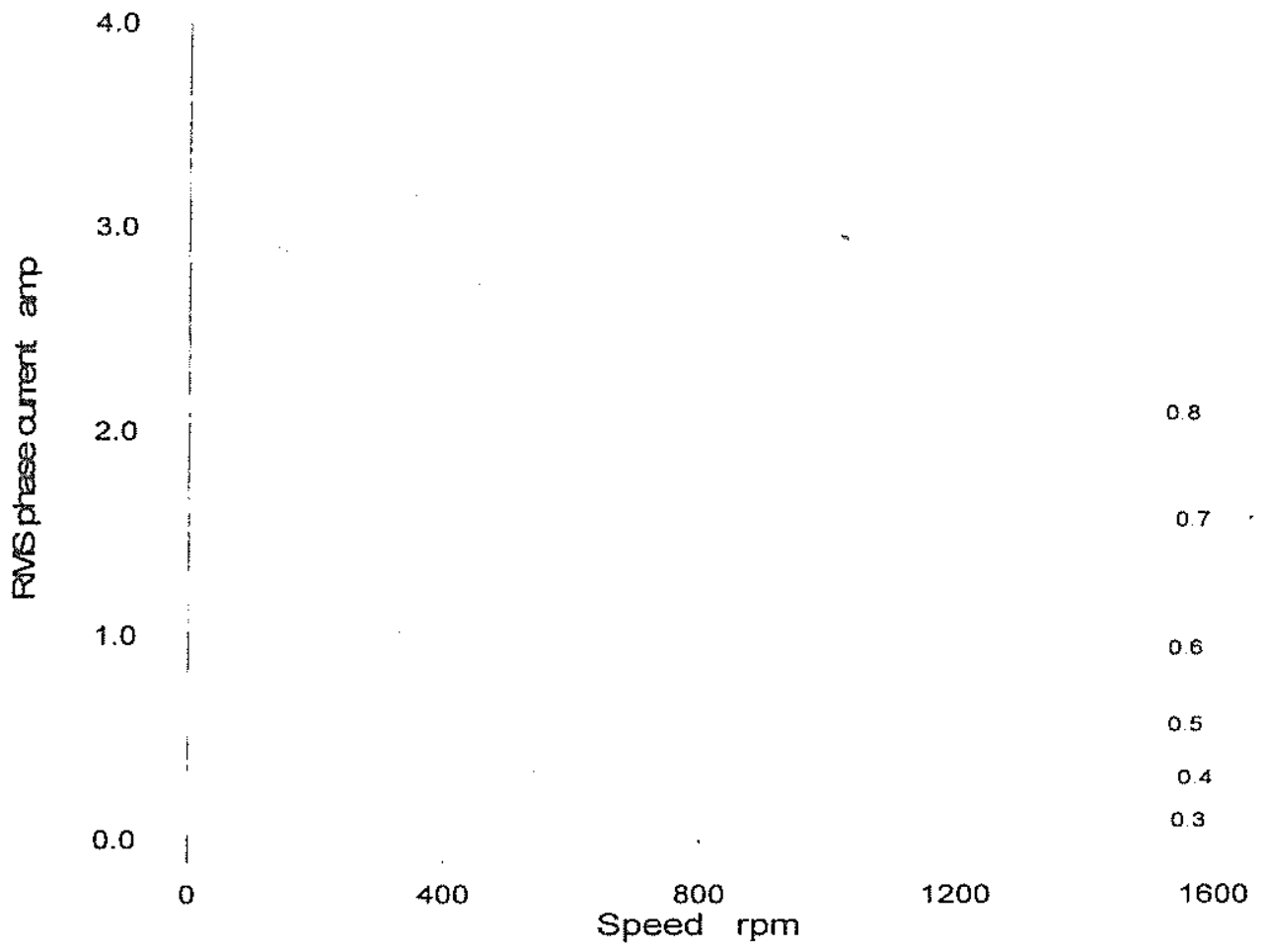

Fig(6) RMS phase current as a function of speed for different commutation ratios (For the first operating condition) 
The second operating condition has also been analyzed and experimentally tested. Figure(7) shows the predicted and measured external load characteristics for different commutation ratios. It is observed that the voltage falls down with the increase of load current. The shape of these characteristics is mainly dependent on the power characteristics of the machine, however, the voltage can be regulated over a wide range of load variations by changing the commutation ratio. This method can be implemented in a closed-loop system for voltage control. Symbols on Fig(7) represent the experimental results while solid-line curves represent the analytical results. Deviations are attributed to analysis approximations.

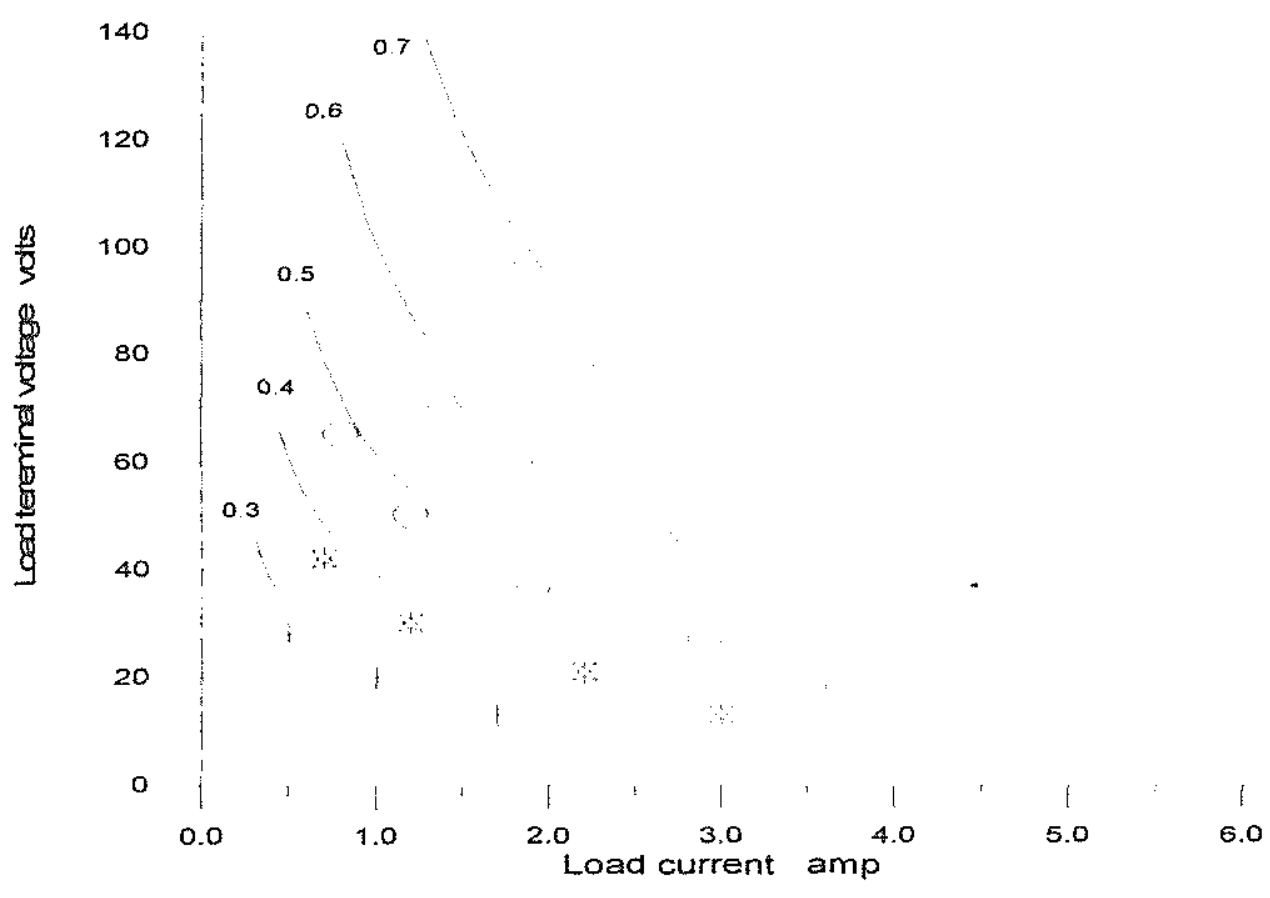

Fig(7) External load characteristics at $1500 \mathrm{rpm}$ for different commutation ratios (For the second operating condition)

The excitation power characteristics are shown in Fig(8). It is observed that the power increase is moderate at low current and becomes higher with higher load current which is due to the machine tendency to produce motor torque as a result of prolonged current pulses.

The load power characteristics are shown in Fig(9). With the increase of the load current the $\psi$-i loop area of the energy converted increases. However further increase results in a fast decrease of that area. This explains the increase and decrease of these characteristics.

In Figs $(8,9)$ there are two reasons for the deviation between measured and predicted results. The first is the approximations in representing the fluxlinkage data and the second is due to neglecting the commutation losses in the analysis. 


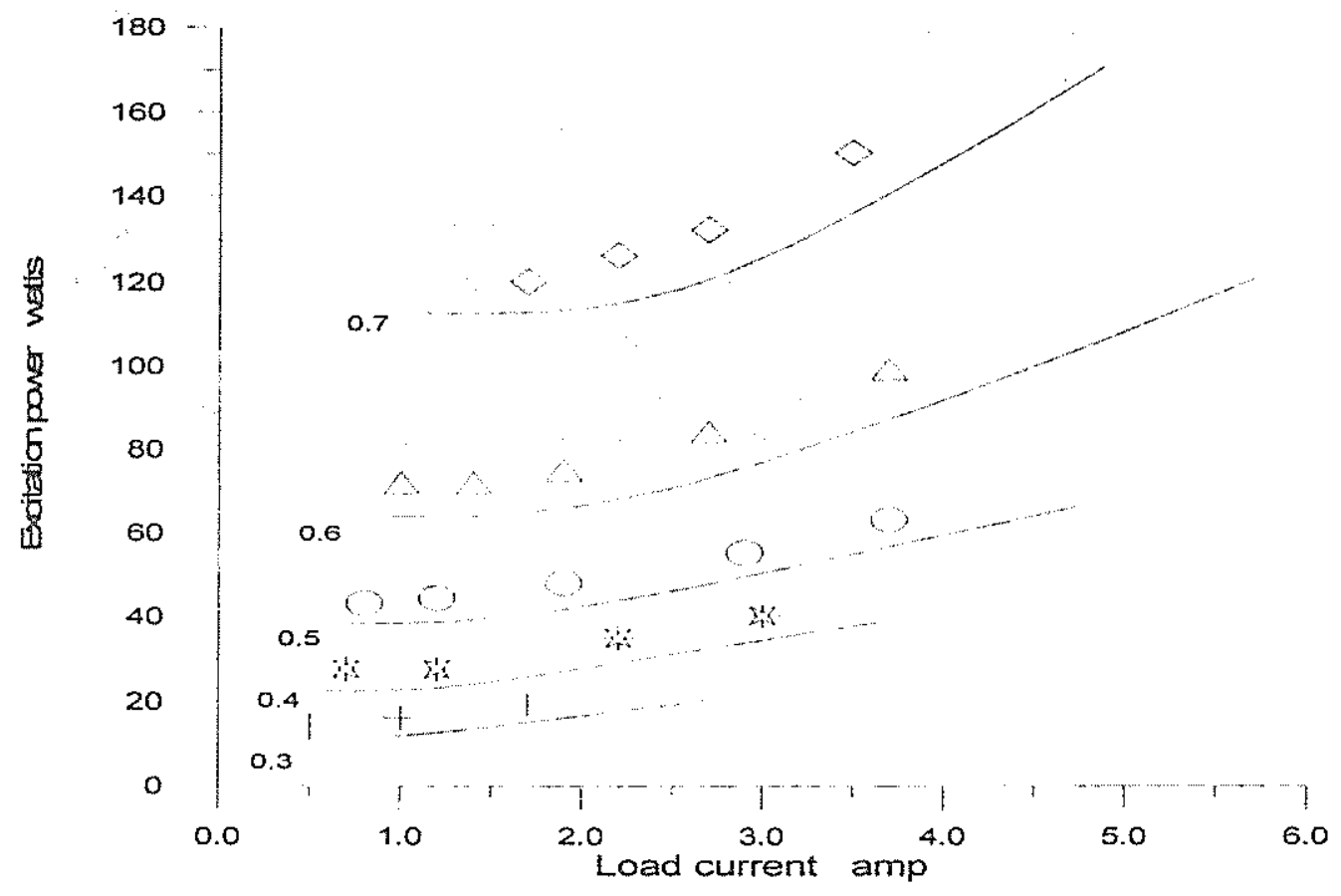

Fig(8) Excitation power characteristics at $1500 \mathrm{rpm}$ and different commutation ratios (For the second operating condition)

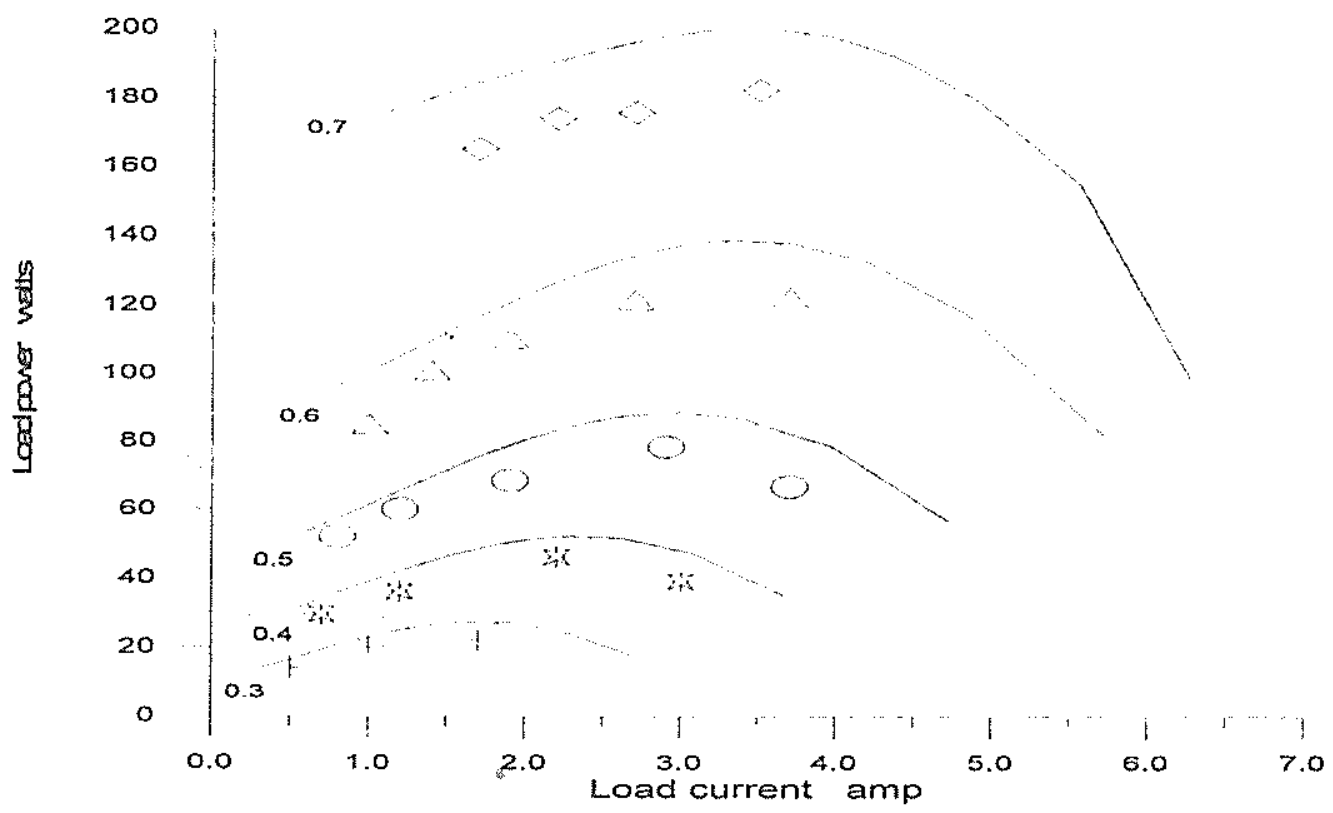

Fig(9) Load power characteristics at $1500 \mathrm{rpm}$ and different commutation ratios, (For the second operating condition) 
The predicted net generated power of the machine is shown in Fig(10) for different commutation ratios. These characteristics are important since they define the limits of the net power zero-crossing points at which the power reverses from positive (generator) to negative (motor) operation. A specific characteristic of SR generator with direct load is that it continues to supply its load after the zero-crossing point but the load power is actually obtained from the excitation source.

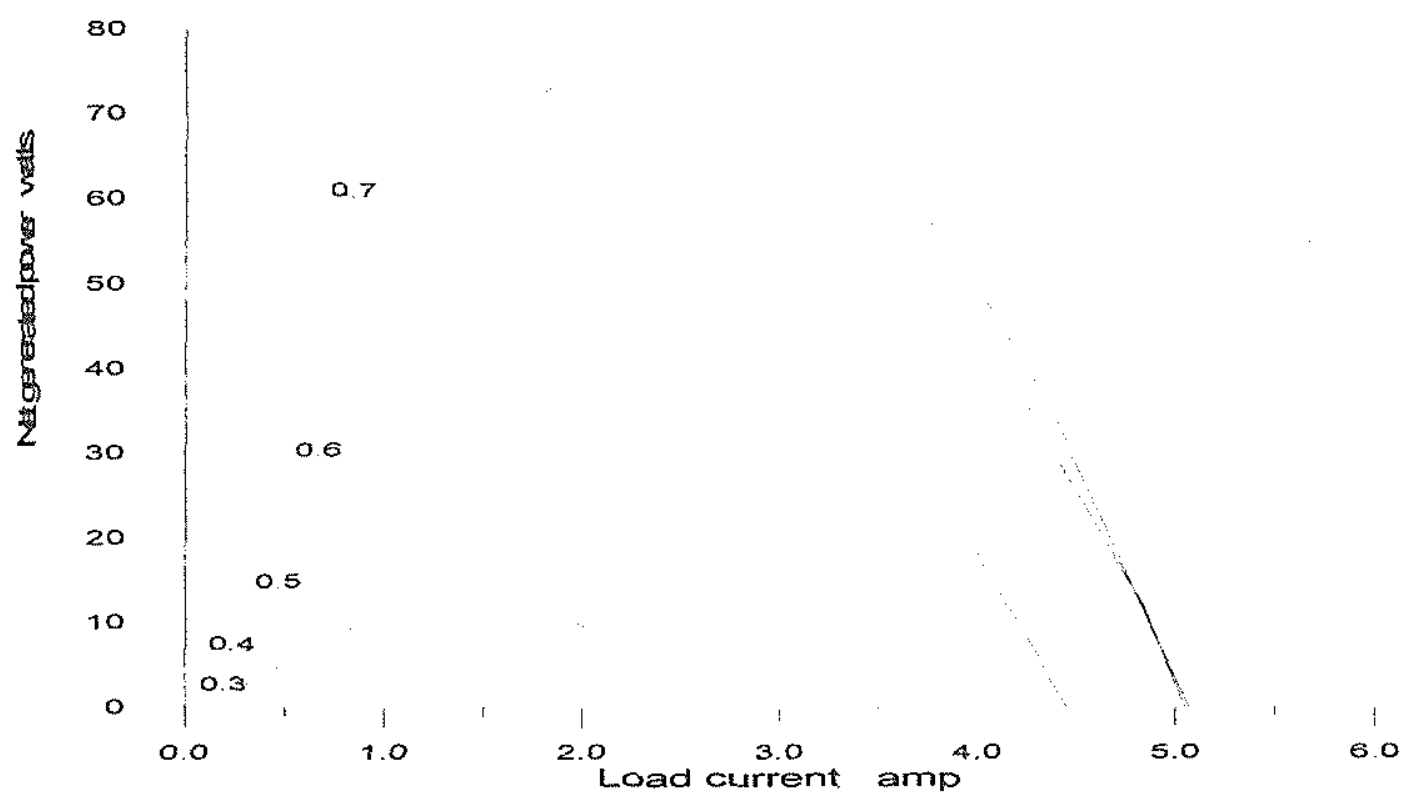

Fig(10) Net generated power characteristics at 1500 rpm and different commutation ratios (For the second operating condition)

The analysis for the second operating condition has been given for commutation ratios up to 0.7 . It has been found that the power decreases for any ratio more than 0.7 for this operating condition which is less than the corresponding commutation ratio for the first operating condition. In the second condition there is no negative voltage applied to the winding after turn-off, and so the current pulse is longer for the same commutation ratio compared with the first one. In such case the machine tends to produce motoring torque earlier than the first operating condition. For the same reason, the generated power for the first condition is generally higher than that of second condition, at the same circumstances, Figs $(5,9)$.

The experimentally recorded excitation voltage and current waveforms for the system are shown in Fig(11). The recorded and calculated load voltage and current waveforms for the loaded machine are shown in Figs(12-a,b). Voltage spikes in the recorded waveform is due to switching process. These spikes can be filtered-out as shown in Fig(13) by connecting a parallel capacitor with the load. 


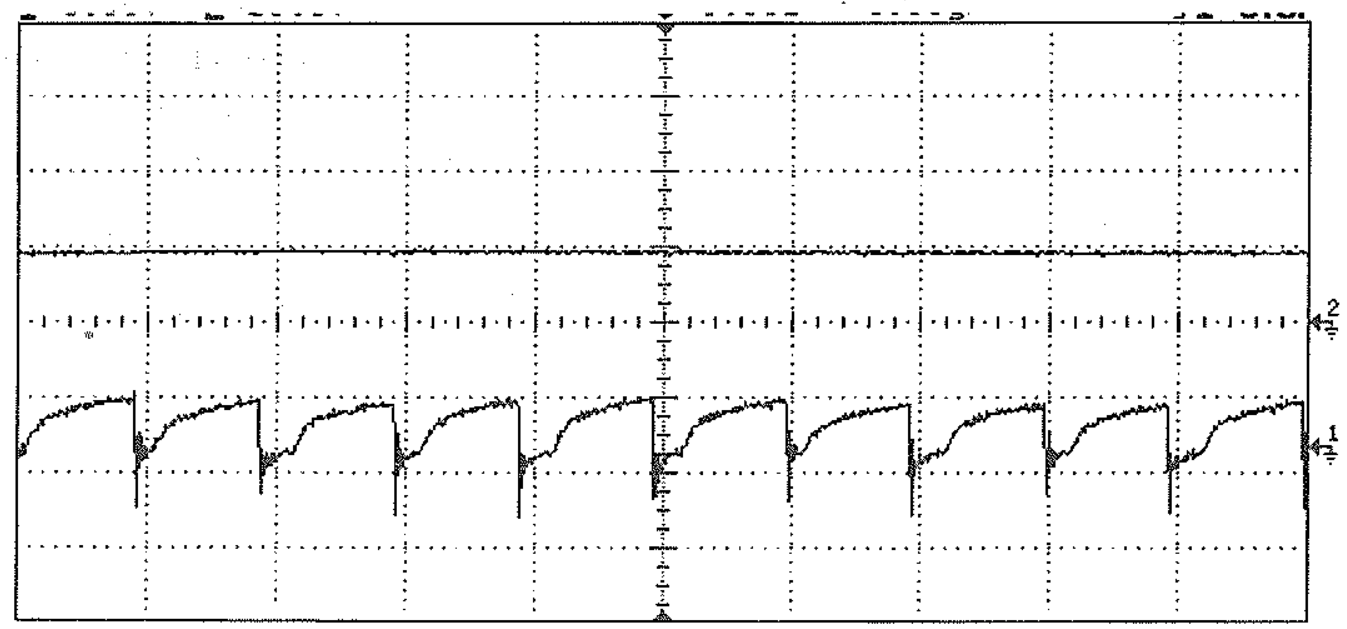

Fig(11) Recorded voltage and current for the excitation source. Top: excitation voltage $50 \mathrm{~V} / \mathrm{Div}$, Bottom: excitation current $1 \mathrm{~A} / \mathrm{Div}$

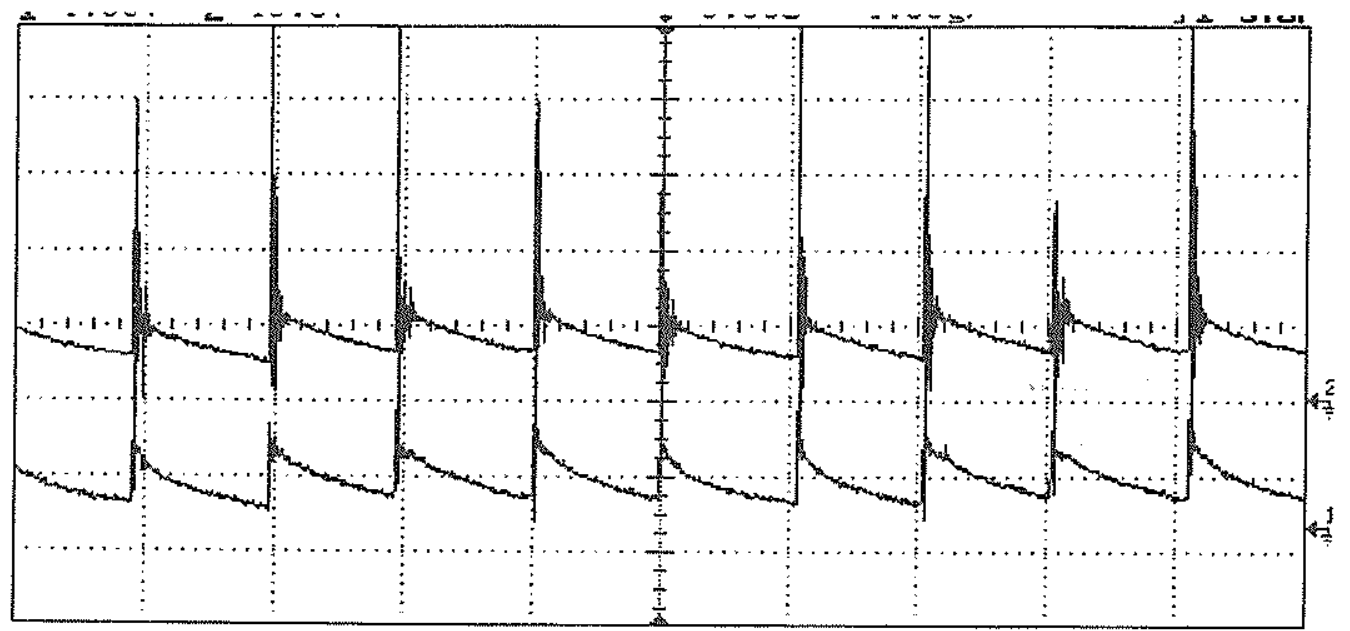

Fig(12-a) Recorded load voltage and current. Top: load voltage 100V/div, Bottom: load current 5A/Div

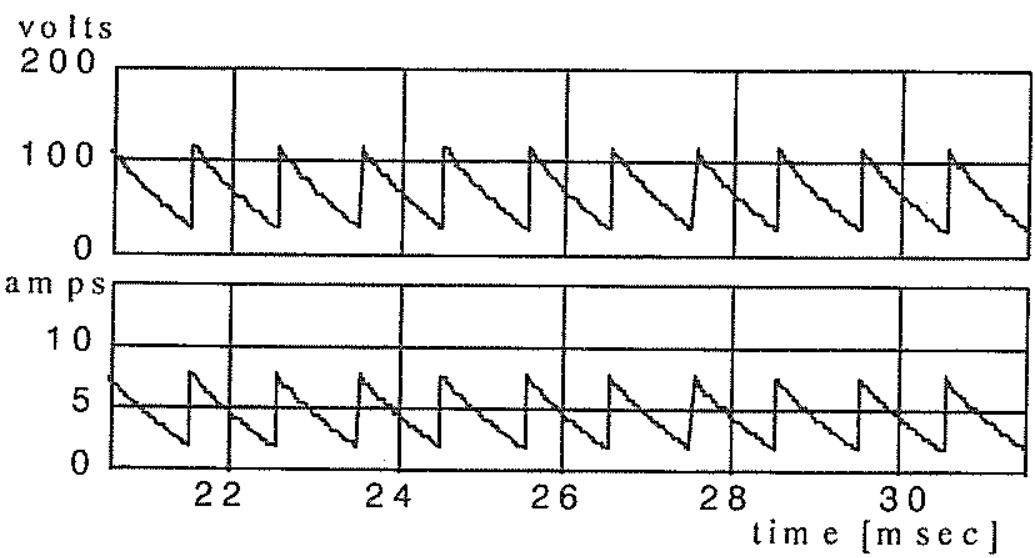

Fig(12-b) Calculated load voltage and current. 


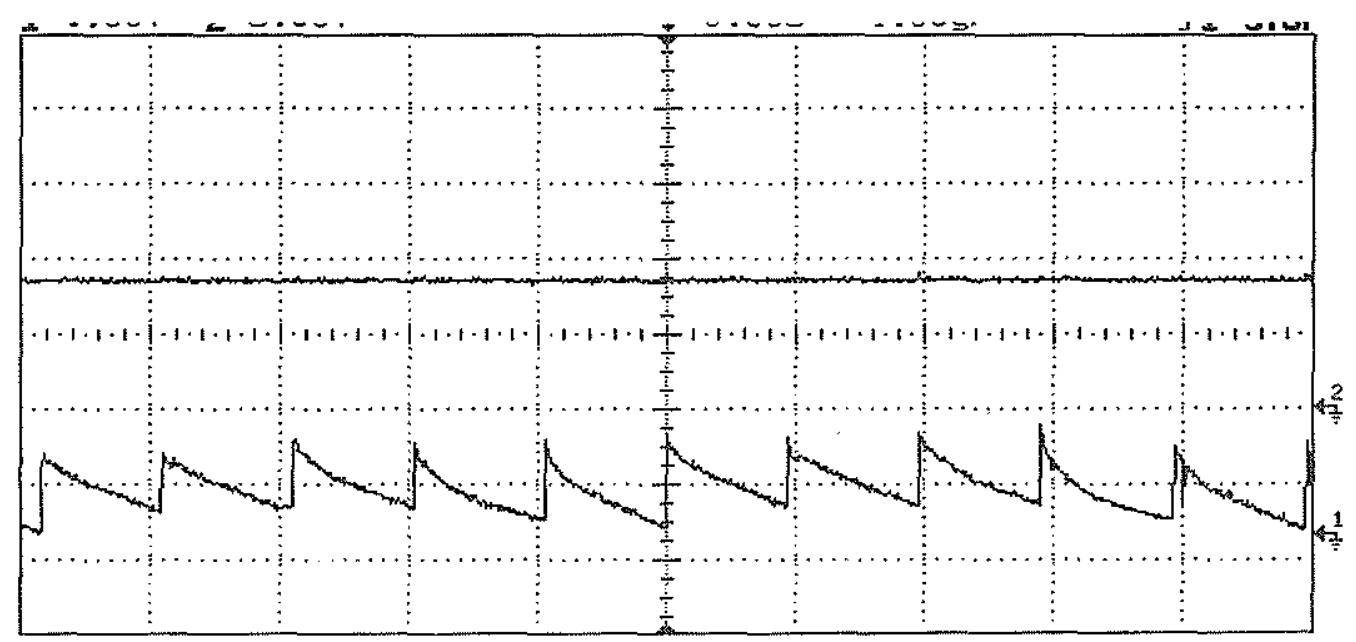

Fig(13) Recorded load voltage and current (with a load capacitor) Top: load voltage $100 \mathrm{~V} / \mathrm{div}$, Bottom: load current 5A/Div

The recorded and calculated phase voltage and current waveforms are shown in Figs $(14-\mathrm{a}, \mathrm{b})$, where the voltage pulses are the excitation pulses drawn from the source. The recorded waveforms clearly show the successful operation of SR machine as a DC generator.

The second operating condition is also suitable for wind turbine applications. In such case, the machine should be connected to a back-up battery system for the excitation continuity.

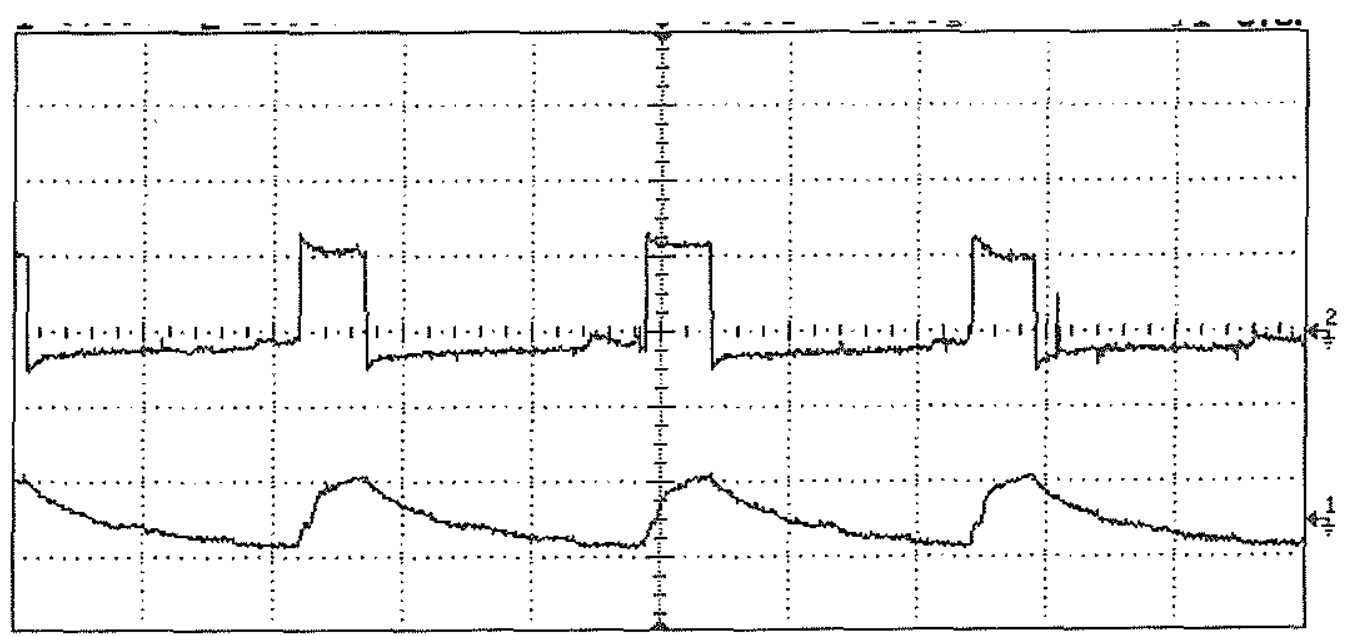

Fig(14-a) Recorded phase voltage and current Top: load voltage 50V/div, Bottom: load current 5A/Div 


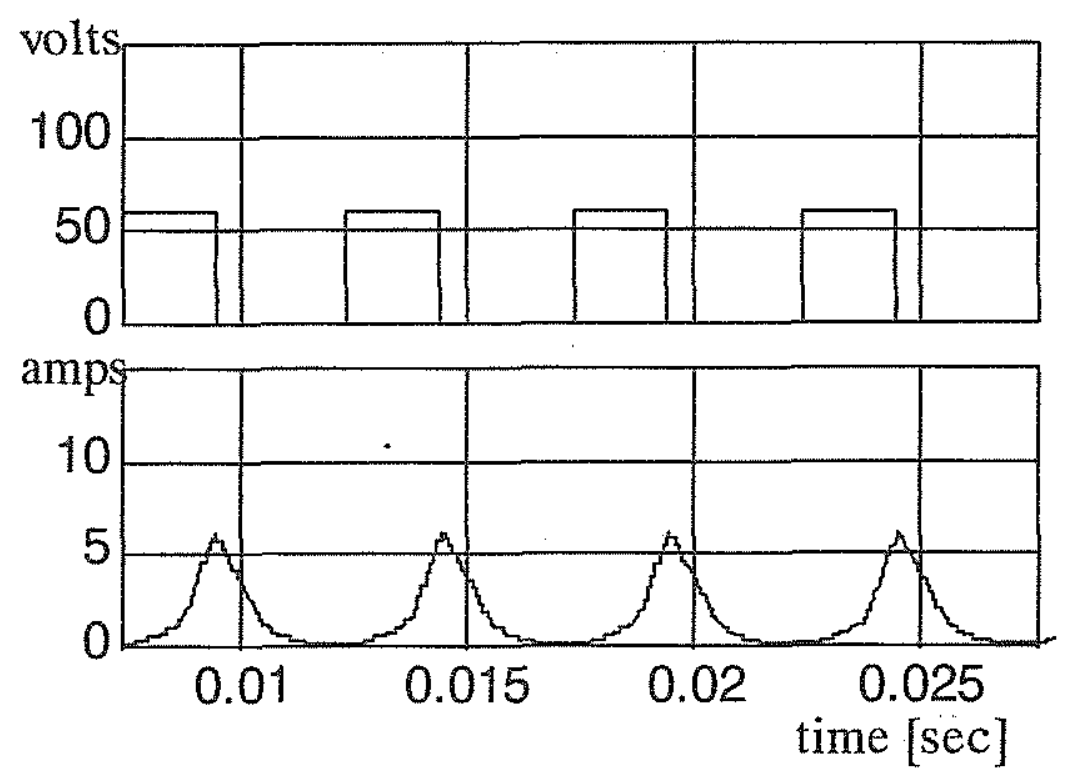

Fig (14-b) Calculated phase voltage and current.

\section{6- Conclusions}

The paper presents an analytical and experimental study for the SR generator. The generator performance has been investigated with a constant voltage dc power source and as a stand alone system. Both systems are possible, however the first operating condition contributes higher power. The power level for the first operating condition and terminal voltage for the second operating condition can be controlled by varying the commutation ratio (e.g. width of the excitation pulses). Experimental and analytical results are in a good agreement. This type of machine cab be considered a competing candidate $\mathrm{dc}$ generator for operation with wind turbines.

\section{7- References}

[1] P.J. Lawrenson, J.M. Stephenson, P.T. Blenkensop, J. Corda, N.N. Fulton, "Variable Speed Switched Reluctance Motor", IEE Proc., Vol 127, Pt. B, No 4, July 1980

[2] P.J. Lawrenson, "Switched Reluctance Drives: a Perspective", International Conference on Electrical Machines ICEM'92, Manchester, UK, 15-17 September 1992, PP 12-21

[3] D. Cameron, and J.H. Lang, "The Control of High-Speed VariableReluctance Generators in Electric Power Systems", IEEE Trans. Industry Applications, Vol. 29, No 6, November/December 1993 
[4] M. Abouzied, "The Wind Driven Photovoltaic Excited Stand-Alone Axial Field Switched Reluctance Generator", Al-Azhar Engineering 4th Conf., Cairo, EGYPT, December 1995, PP 374-383

[5] M. Abouzied, B.W. Williams and Y.G. Dessouky, "Experimental Implementation of Separately Excited Switched Reluctance Generator", 5th International Middle East Power Conference MEPCON'97, Alexandria, EGYPT

[6] J. Stephenson and J. Corda, "Computation of Torque and Current in Doubly Salient Reluctance Motors From Nonlinear Magnetization Data", IEE Proc., Vol 126, Pt. B, No 5, May 1979

[7] M. M. Khater, A. A. Hassanein , M. M. El-Shanawany and B. W. Williams, "Five-Phase Switched Reluctance Motor. Part 1: Design and Performance.", Engineering Research Bulletin, Vol 17, Part 1,1994, Faculty of Engineering, Menoufiya University, Shebin El-Kom, EGYPT 


\section{تشفيل وألداء مولد الممانعة المغناطيسية ذو التيار النبضهى}

د. محمود مصطفى خاطر د د. سلوى محمد رياض طاهون

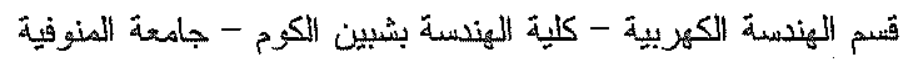

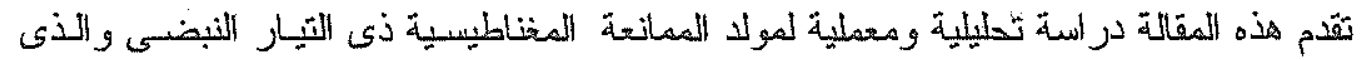

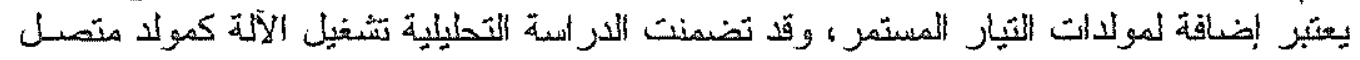

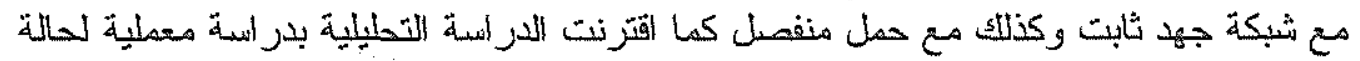

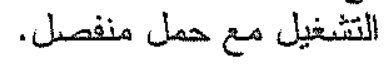

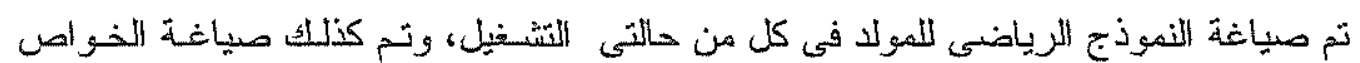

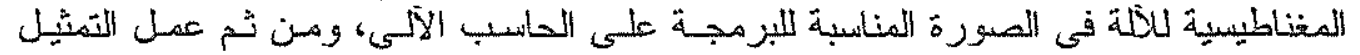

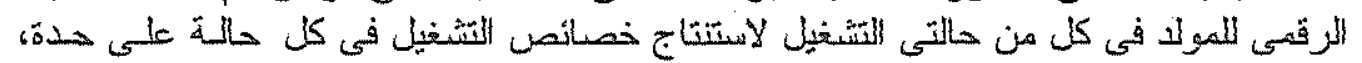

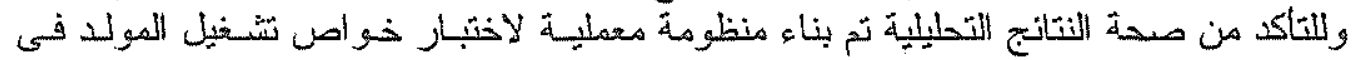

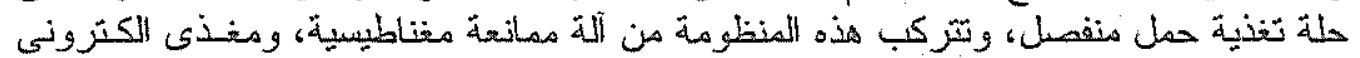

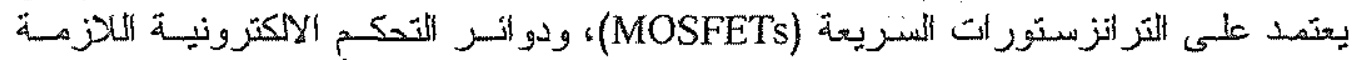

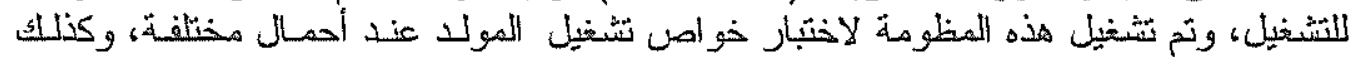

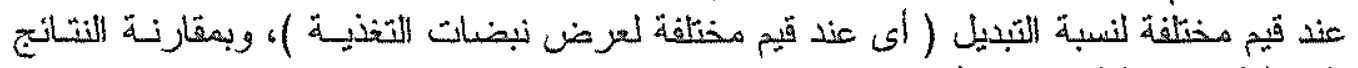
المعطلية و التحطيلية تبين التطابق بينهما.

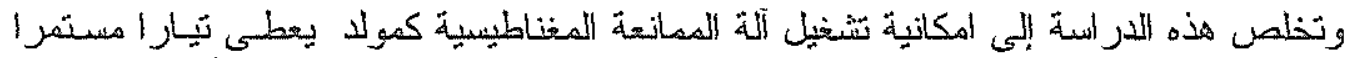

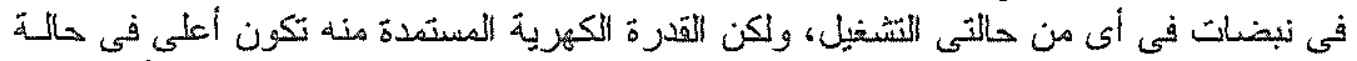

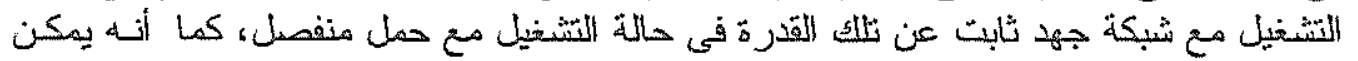

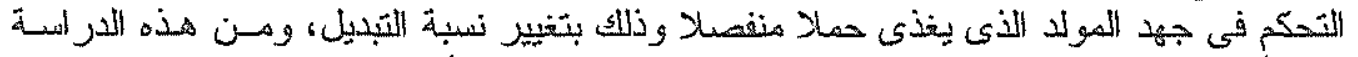

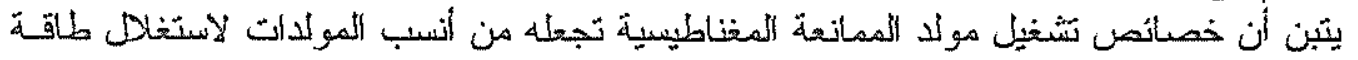
اللزياح فى توليد الكهرباء. 